Please do not remove this page

RMIT

UNIVERSITY

\title{
Mixed-mode high-power impulse magnetron sputter deposition of tetrahedral amorphous carbon with pulse-length control of ionization
}

Tucker, M; Ganesan, R.; McCulloch, D; Partridge, J; Stueber, M; Ulrich, S; Bilek, M.

https://researchrepository.rmit.edu.au/esploro/outputs/9921860300001341/filesAndLinks?institution=61RMIT_INST\&index=null

Tucker, M., Ganesan, R., McCulloch, D., Partridge, J., Stueber, M., Ulrich, S., Bilek, M., McKenzie, D., \& Marks, N. (2016). Mixed-mode high-power impulse magnetron sputter deposition of tetrahedral amorphous carbon with pulse-length control of ionization. Journal of Applied Physics, 119(15), 1-6. https://doi.org/10.1063/1.4946841

Document Version: Published Version

Published Version: https://doi.org/10.1063/1.4946841

Repository homepage: https://researchrepository.rmit.edu.au (c) 2016 Author(s).

Downloaded On 2023/04/26 12:02:18 +1000 
Thank you for downloading this document from the RMIT Research Repository.

The RMIT Research Repository is an open access database showcasing the research outputs of RMIT University researchers.

RMIT Research Repository: http://researchbank.rmit.edu.aul

\section{Citation:}

Tucker, M, Ganesan, R, McCulloch, D, Partridge, J, Stueber, M, Ulrich, S, Bilek, M, McKenzie, D and Marks, N 2016, 'Mixed-mode high-power impulse magnetron sputter deposition of tetrahedral amorphous carbon with pulse-length control of ionization', Journal of Applied Physics, vol. 119, no. 15, 155303, pp. 1-6.

\section{See this record in the RMIT Research Repository at:}

https://researchbank.rmit.edu.au/view/rmit:36936

Version: Published Version

\section{Copyright Statement:}

(C) 2016 Author(s).

\section{Link to Published Version:}

https://dx.doi.org/10.1063/1.4946841 


\section{Mixed-mode high-power impulse magnetron sputter deposition of tetrahedral amorphous carbon with pulse-length control of ionization}

Cite as: J. Appl. Phys. 119, 155303 (2016); https://doi.org/10.1063/1.4946841

Submitted: 05 February 2016. Accepted: 03 April 2016. Published Online: 21 April 2016

M. D. Tucker, R. Ganesan, D. G. McCulloch, J. G. Partridge, M. Stueber, S. Ulrich, M. M. M. Bilek, D. R.

McKenzie (D), and N. A. Marks

ARTICLES YOU MAY BE INTERESTED IN

Tutorial: Reactive high power impulse magnetron sputtering (R-HiPIMS)

Journal of Applied Physics 121, 171101 (2017); https://doi.org/10.1063/1.4978350

Synthesis of hydrogenated diamondlike carbon thin films using neon-acetylene based high power impulse magnetron sputtering discharges

Journal of Vacuum Science \& Technology A 34, 061504 (2016); https://

doi.org/10.1116/1.4964749

Evolution of target condition in reactive HiPIMS as a function of duty cycle: An opportunity for refractive index grading

Journal of Applied Physics 121, 171909 (2017); https://doi.org/10.1063/1.4977824

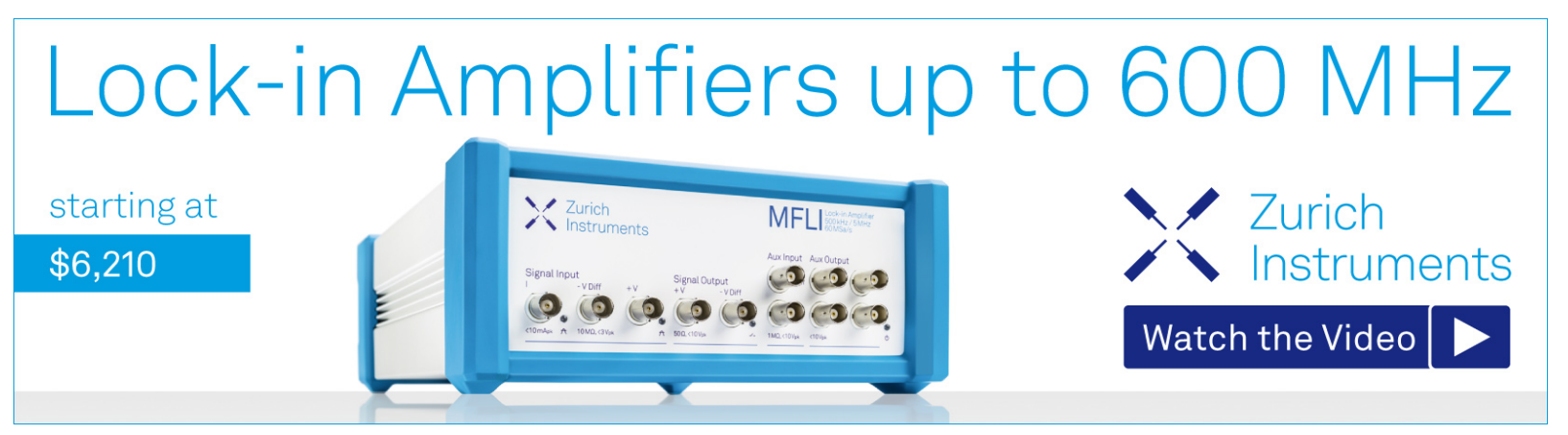




\title{
Mixed-mode high-power impulse magnetron sputter deposition of tetrahedral amorphous carbon with pulse-length control of ionization
}

\author{
M. D. Tucker, ${ }^{1}$ R. Ganesan, ${ }^{2}$ D. G. McCulloch, ${ }^{3}$ J. G. Partridge,${ }^{3}$ M. Stueber,${ }^{4}$ S. Ulrich, ${ }^{4}$ \\ M. M. M. Bilek, ${ }^{2}$ D. R. McKenzie, ${ }^{2}$ and N. A. Marks ${ }^{1}$ \\ ${ }^{1}$ Department of Physics and Astronomy, Curtin University, Perth, Western Australia 6102, Australia \\ ${ }^{2}$ School of Physics, The University of Sydney, Sydney, New South Wales 2006, Australia \\ ${ }^{3}$ School of Applied Sciences, RMIT University, GPO Box 2476, Melbourne, Victoria 3001, Australia \\ ${ }^{4}$ Karlsruhe Institute of Technology—KIT, Institute for Applied Materials-IAM, Hermann-von-Helmholtz-Platz 1, \\ 76344 Eggenstein-Leopoldshafen, Germany
}

(Received 5 February 2016; accepted 3 April 2016; published online 21 April 2016)

\begin{abstract}
High-power impulse magnetron sputtering (HiPIMS) is used to deposit amorphous carbon thin films with $s p^{3}$ fractions of $13 \%$ to $82 \%$. Increasing the pulse length results in a transition from conventional HiPIMS deposition to a "mixed-mode" in which an arc triggers on the target surface, resulting in a large flux of carbon ions. The films are characterized using X-ray photoelectron spectroscopy, Raman spectroscopy, ellipsometry, nanoindentation, elastic recoil detection analysis, and measurements of stress and contact angle. All properties vary in a consistent manner, showing a high tetrahedral character only for long pulses, demonstrating that mixed-mode deposition is the source of the high carbon ion flux. Varying the substrate bias reveals an "energy window" effect, where the $s p^{3}$ fraction of the films is greatest for a substrate bias around $-100 \mathrm{~V}$ and decreases for higher or lower bias values. In the absence of bias, the films' properties show little dependence on the pulse length, showing that energetic ions are the origin of the highly tetrahedral character. Published by AIP Publishing. [http://dx.doi.org/10.1063/1.4946841]
\end{abstract}

\section{INTRODUCTION}

Amorphous carbon thin films have been extensively studied for decades and have found numerous technological applications. ${ }^{1,2}$ This interest is due to the possibility of controlling the proportions of $s p^{2}$ and $s p^{3}$ bonding as well as the flexibility afforded by a wide variety of deposition techniques including evaporation, sputtering, ion-beam deposition, cathodic arcs, and chemical vapour deposition. Tetrahedral amorphous carbon $(t a-\mathrm{C})$ and hydrogenated $t a-\mathrm{C}(t a-\mathrm{C}: \mathrm{H})$ are often desired due to their diamond-like properties, while in many industrial applications, amorphous carbon $(a-\mathrm{C})$ and hydrogenated $a$-C $(a-\mathrm{C}: \mathrm{H})$ do an excellent job as well. This range of possibilities means that amorphous carbon coatings are found in applications ranging from the automotive industry, where tribological performance is important, to medical devices, where surface energies and wetting behaviour are of concern.

Carbon deposition sources that generate a high fraction of ions are particularly attractive as they offer control of the kinetic energy of the depositing flux. Energetic ions result in dense films, and even when the carbon ion fraction is minimal, such as in sputtering, it is possible to synthesize dense and hard amorphous carbon films by bombarding the growing film with argon ions, either by using a substrate bias $^{3}$ or by using a separate $\mathrm{Ar}$ ion source. ${ }^{4}$ With a highly ionized carbon plasma, such as produced by cathodic arc deposition, laser ablation, or mass-selected ion beam deposition, optimal energies of $\sim 100 \mathrm{eV}$ produce tetrahedral amorphous carbon (ta-C) films with $s p^{3}$ fractions as high as $85 \% .^{5-7}$ There have also been many attempts to deposit $t a-\mathrm{C}$ using sputtering techniques, ${ }^{4,8,9}$ which are attractive due to their ubiquity in large-scale coating. However, these efforts are hindered by the near absence of carbon ions in the sputtered flux of a conventional magnetron, limiting the ability to control the incident ion energy. High Power Impulse Magnetron Sputtering (HiPIMS $)^{10-15}$ has been found to increase the ionized fraction when sputtering metals, ${ }^{16}$ but for carbon, the effect is small and the films remain predominantly $s p^{2}$ bonded. ${ }^{17-26}$

We have recently demonstrated a new process in which HiPIMS sputtering is repeatedly driven into an arc mode. ${ }^{27}$ Using this "mixed-mode," we synthesized $t a-\mathrm{C}$ with an $s p^{3}$ fraction of $80 \%$ as shown by electron energy loss spectroscopy (EELS) and X-ray photoelectron spectroscopy (XPS). ${ }^{28}$ The defining characteristic of mixed-mode operation is that the magnetron current increases to a degree such that an arc ignites on the surface of the carbon target. ${ }^{27,29}$ The arcs exhibit characteristics of carbon cathodic arcs including retrograde motion in a magnetic field, fractal-like branching of the arc spots, and a minimum average ion energy of $20 \mathrm{eV}$. $^{28}$ These arcs result in increased ionization in the depositing flux and are the means by which the high $s p^{3}$ fraction of the films is obtained. Deposition of $t a-\mathrm{C}$ films required Ar pressures of $0.3 \mathrm{~Pa}$ or lower. At higher pressures, all the measures of the tetrahedral character of the films deteriorated, presumably due to a decreased ion flux at the substrate caused by chargeexchange scattering with Ar neutrals.

In this article, we explore the transition from conventional HiPIMS to mixed-mode by varying the pulse length of the magnetron power supply. The carbon films are characterized using XPS, Raman spectroscopy, ellipsometry, and stress and contact angle measurements. We demonstrate that the presence of arcing is critical for the synthesis of $t a-\mathrm{C}$; for shorter pulses where arcing is absent, the $s p^{3}$ fraction is very low. We also study the effect of substrate bias, reproducing 
the well-known "energy window" effect in which the $s p^{3}$ fraction is maximal for a bias of approximately $100 \mathrm{~V} .^{30}$ Together, these two data sets confirm that $t a-\mathrm{C}$ can be synthesized with a magnetron sputtering source and demonstrate that an ionized flux produced by arcing is the source of the high $s p^{3}$ fraction and associated properties. The full spectrum of amorphous carbon structures is accessible by varying the magnetron pulse profile and substrate bias voltage, enabling the film properties to be tuned for specific applications.

\section{EXPERIMENTAL DETAILS}

Films were deposited in an AJA sputtering system using an AJA A330 magnetron source fitted with a $76 \mathrm{~mm}$ diameter high-density graphite target of $99.99 \%$ purity. The base vacuum of the system was $10^{-5} \mathrm{~Pa}$; during sputtering, Ar was introduced to the chamber and an automatic gate valve was used to regulate the pressure to 0.3 Pa. A RUP7 (GBS Elektronik, Dresden) power supply was used to drive the magnetron with one of the five different pulse lengths $(90,120,150,180$, and $210 \mu \mathrm{s})$ at a rate of $100 \mathrm{~Hz}$. The power supply current was measured using the power supply's built-in Hall effect current transducer (LEM LF-1005-S). Typical current traces are shown in Figure 1. The charging voltage used was $720 \mathrm{~V}$, except for the case of the longest pulse length $(210 \mu \mathrm{s})$ where $640 \mathrm{~V}$ was used to avoid triggering the current limit of the power supply. Samples were deposited on (100) silicon substrates positioned $220 \mathrm{~mm}$ from the magnetron target surface. The deposition time was $60 \mathrm{~min}$, resulting in films with thicknesses between 25 and $100 \mathrm{~nm}$. The deposition rate as a function of pulse length and substrate bias is shown in Figure 2.

XPS was carried out using an $\mathrm{Al} \mathrm{K}_{\alpha} \mathrm{X}$-ray source. The resulting spectra were fitted, using the program CasaXPS, with a Shirley background, Gaussian-Lorentzian product line shapes at $285.2 \pm 0.1 \mathrm{eV}$ and $284.4 \pm 0.1 \mathrm{eV}$ corresponding to $s p^{3}$ and $s p^{2}$-hybridized carbon, and two smaller peaks corresponding to carbon-oxygen bonding. ${ }^{31}$ The optical constants and thicknesses of the films were determined using variable angle spectroscopic ellipsometry. Spectroscopic scans over the wavelength range $192.5-1000 \mathrm{~nm}$ were collected at incident angles of 60,65 , and $70^{\circ}$. A Cauchy dispersion model

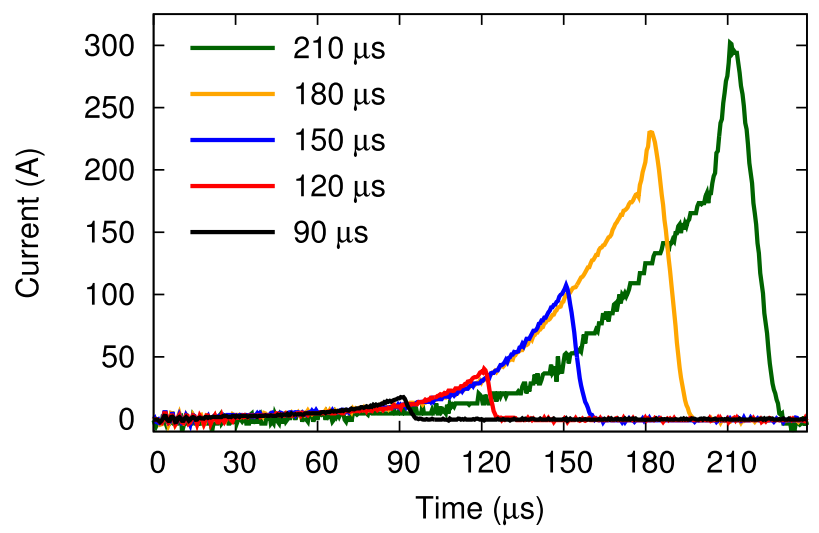

FIG. 1. Evolution of the magnetron current during HiPIMS pulses of various lengths. The power supply charging voltage was $720 \mathrm{~V}$, except for the $210 \mu$ s pulse where a lower value of $640 \mathrm{~V}$ was used. The change in slope preceding the maximum of the 180 and $210 \mu$ s traces corresponds to the ignition of an arc.

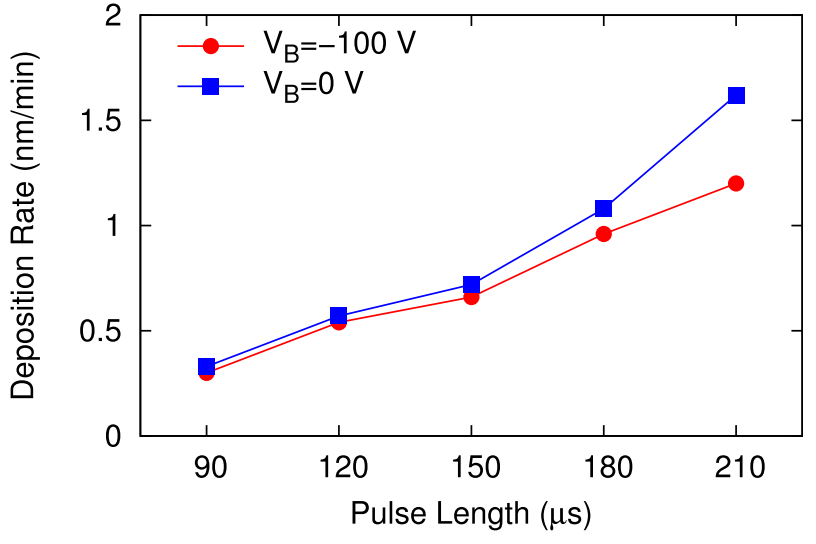

FIG. 2. Deposition rate as a function of pulse length and substrate bias. Film thicknesses were determined by ellipsometry as described in the text.

was used to fit the data and extract the refractive index and extinction coefficient. The thickness determined by ellipsometry was also confirmed by stylus profiler step measurements. Raman spectra were measured using a $514.5 \mathrm{~nm}$ excitation laser and fitted with a Breit-Wigner-Fano (BWF) asymmetric Lorentzian lineshape to obtain the fitting parameter $Q$, which quantifies the asymmetry of the peak.

The intrinsic compressive stress in the films was measured by using a profilometer to measure the wafer curvature and applying Stoney's equation. ${ }^{32}$ Contact angle measurements were taken using a drop shape analyser using $45 \mu \mathrm{l}$ drops of water and diiodomethane; the surface energy was then obtained using Young's equation. Hydrogen content was measured by elastic forward recoil detection analysis (ERDA) on a $2 \mathrm{MV}$ tandem ion accelerator, and the total $\mathrm{H}$ content was calculated relative to Kapton, which has a $\mathrm{H}$ content of 24 at.\%. The films were imaged with a Dimension 3100 atomic force microscope (AFM) operating in the tapping mode. These data were analysed using the Gwyddion software package to compute root-mean-square roughness values. Nanoindentation measurements were carried out with a Hysitron instrument fitted with a Berkovich indenter. The film was indented with a maximum force of $200 \mu \mathrm{N}$, producing indents of a depth of less than $10 \mathrm{~nm}$. The loaddisplacement data were analyzed to determine the reduced modulus by fitting the Hertzian equation to the initial portion of the loading curve as described in Ref. 33. This method was used because the very high elastic recovery of the films meant that the Oliver-Pharr method ${ }^{34}$ was not appropriate.

\section{RESULTS}

Our results are presented in two parts. First, we present characterization of films deposited using mixed-mode deposition with a comparatively long pulse length. As shown in our earlier Letter, ${ }^{28}$ this manner of deposition, combined with a substrate bias of $-100 \mathrm{~V}$, results in the synthesis of ta-C. Here, we provide further detail on the underlying data and their analysis and also present new information on hydrogen content and mechanical properties. Additionally, we demonstrate that there is an ion energy window that is optimal for producing $t a-\mathrm{C}$. In the second part of the results section, we vary the HiPIMS pulse length and so transit from 
a pure HiPIMS discharge to mixed-mode conditions. The role of ions in the deposition flux is studied by depositing films under conditions of zero and $-100 \mathrm{~V}$ substrate bias, and characterization is performed on bulk and surface properties.

\section{A. Mixed-mode deposition}

Figure 3 shows the XPS spectrum for a $t a$-C film prepared with a pulse length of $210 \mu$ s, which results in an arc igniting during every pulse. The substrate bias was $-100 \mathrm{~V}$. The XPS spectrum is fitted by a large peak at $285.2 \mathrm{eV}$ corresponding to $s p^{3}$ bonding, a smaller peak at $284.4 \mathrm{eV}$ corresponding to $s p^{2}$ bonding, and smaller peaks associated with carbon-oxygen bonds, likely due to surface contamination. The $s p^{3}$ fraction inferred from the fit is $81 \%$, very similar to the values reported in our recent work ${ }^{28}$ in which EELS measurements of the K-edge gave a value of $79 \%$. This agreement demonstrates that for these samples XPS is a reliable means of determining the $s p^{3}$ fraction.

Figure 4 shows data obtained via ellipsometry for the same film as examined in Figure 3. Panel (a) shows the wavelength dependence of the refractive index $n$ and extinction coefficient $k$ as obtained from the fitted model. The latter is small across most of the visible spectrum $\left(k=6 \times 10^{-5}\right.$ at $550 \mathrm{~nm})$, consistent with the transparent appearance of the films. Panel (b) shows a Tauc plot in which the quantity $\sqrt{\alpha E}$, where $\alpha=4 \pi k / \lambda$ is the absorption coefficient, is plotted as a function of the photon energy $E$. A linear fit to the data above $3.5 \mathrm{eV}$ yields a Tauc optical gap of $2.66 \mathrm{eV}$, comparable to literature values ${ }^{7}$ for $t a-C$. At lower energies, $\sqrt{\alpha E}$ falls away quickly, indicating relatively few tail states in the gap.

The hydrogen content of the film examined in Fig. 3 was measured using ERDA. The very low value obtained, 0.3 at. $\%$, demonstrates that the high $\mathrm{sp}^{3}$ fraction is indicative of $t a-\mathrm{C}$, rather than any passivation due to hydrogen. This result is supported by nanoindentation measurements (Fig. 5), which yielded a reduced modulus of $345 \mathrm{GPa}$. This value is very similar to recent measurements ${ }^{33}$ of $t a$-C deposited using a filtered-cathodic-arc for which a value of $360 \mathrm{GPa}$ was obtained using the same equipment and analysis methodology. The load-unload characteristic in Fig. 5 shows that after indentation, the film recovered from the elastic deformation

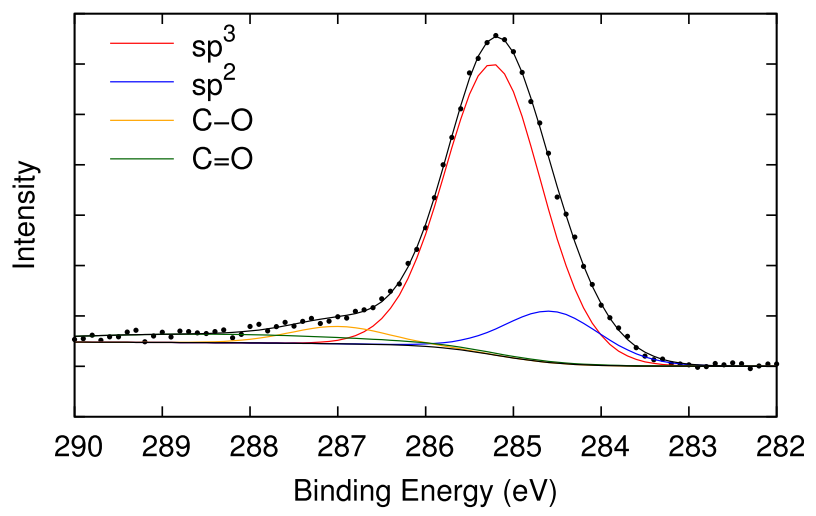

FIG. 3. XPS spectrum for a $t a-C$ film deposited with a pulse length of $210 \mu \mathrm{s}$ and a substrate bias of $-100 \mathrm{~V}$. The experimental data are shown as black points; the black line is the sum of the fitted components.
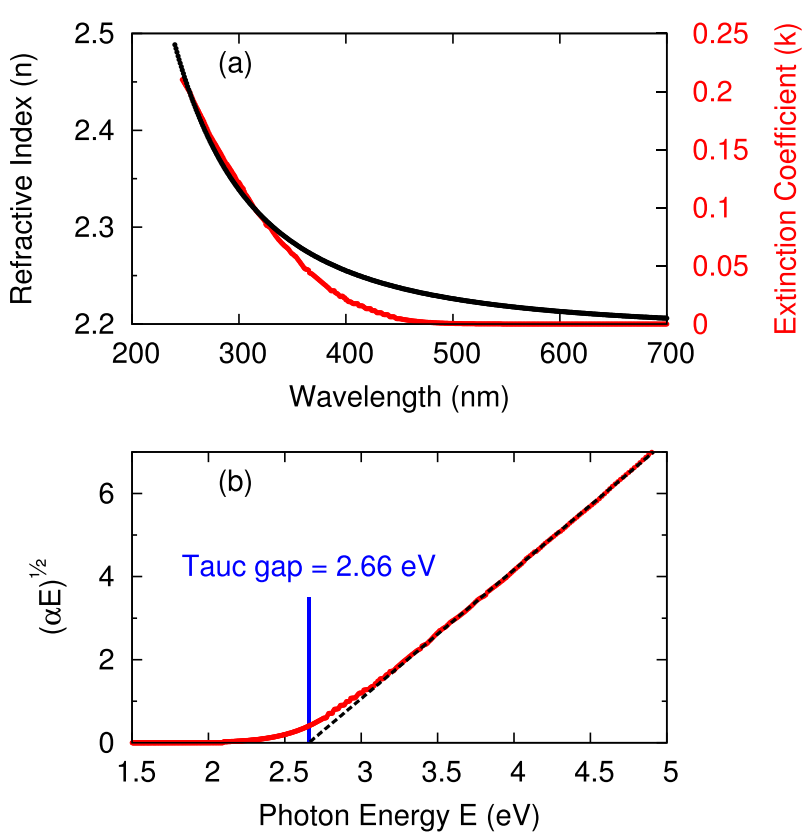

FIG. 4. Ellipsometry-derived data for the same ta-C sample as presented in Figure 3. (a) Refractive index (black) and extinction coefficient (red) obtained from the fitted model described in the text. (b) Tauc plot of the optical gap obtained using the extinction coefficient.

completely and no residual indent impression remained. This type of elastic behaviour is typical of ta-C. . $^{33,35,36}$

The highly $s p^{3}$ bonded film examined in Figures 3 and 4 was deposited with a substrate bias of -100 V. For Figure 6, the substrate bias was varied, with the other deposition parameters held at similar values $(200 \mu \mathrm{s}, 660 \mathrm{~V}, 80 \mathrm{~Hz}$, $19 \mathrm{~cm}$ ) to those used elsewhere in this work. The $s p^{3}$ fraction, as measured by XPS, exhibits the characteristic energy window effect seen in ion beam studies of carbon coatings in which the $s p^{3}$ fraction is maximal for a bias around $-100 \mathrm{~V}$ and declines substantially at higher and lower values. Even in the absence of other evidence, this result demonstrates that the deposition flux contains a large fraction of carbon ions.

\section{B. Varying the pulse length}

By varying the pulse length, the discharge can be operated in a pure HiPIMS mode and in a mixed-mode. As seen earlier in Figure 1, pulses shorter than $150 \mu$ s do not trigger

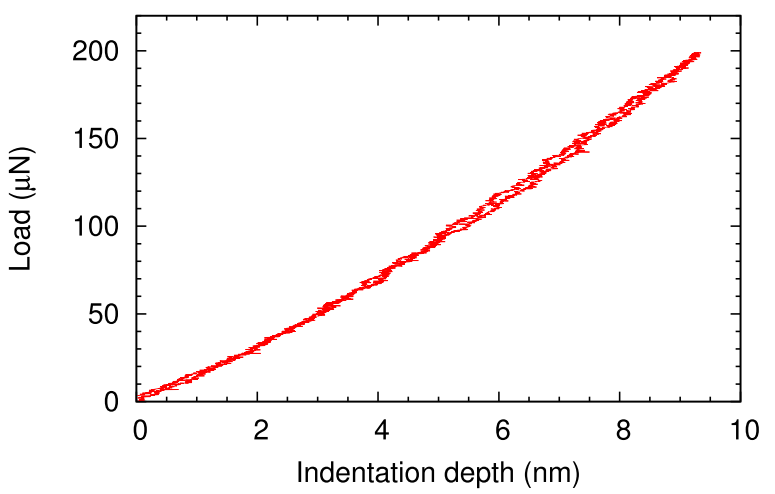

FIG. 5. Force vs displacement curve for a load/unload cycle using a Berkovich indenter on the same ta-C sample presented in Figure 3. The data shown are an average of four indents. 


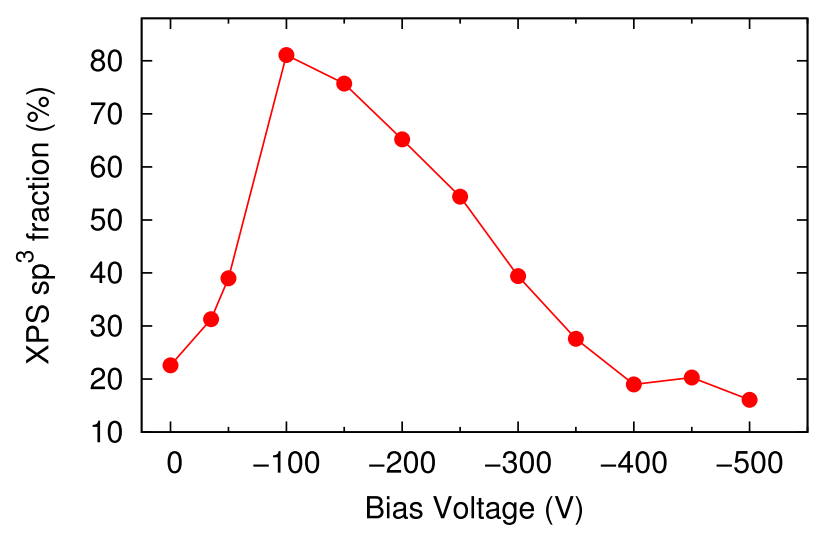

FIG. 6. The $s p^{3}$ fraction as determined by XPS of carbon films as a function of substrate bias voltage. The pulse length chosen $(200 \mu \mathrm{s})$ corresponds to mixed-mode deposition.

arcs, whereas longer pulses trigger increasingly longer arcs, moving further into the mixed-mode regime as the pulse length increases. For intermediate pulse lengths, arcs trigger only on some pulses: no arc ignited during the typical $150 \mu \mathrm{s}$ pulse shown, but occasional arcs were observed at this pulse length.

Figures 7 and 8 show XPS and Raman spectra for samples deposited with five different pulse lengths. The other deposition conditions were the same as those used to deposit the samples examined in Figures 3 and 4.

In Figure 7, a pronounced shift can be seen in the position of the maximum XPS intensity as the pulse length increases. This shift corresponds to a gradual transition from $s p^{2}$ to $s p^{3}$ bonding. Fitting of components to the $90 \mu$ s data shows that the dominant contribution is the peak at $284.4 \mathrm{eV}$ associated with $s p^{2}$ bonding, whereas the fitted spectrum for the $210 \mu$ s sample (already shown in Figure 3) is dominated by the $s p^{3}$ peak. The $s p^{3}$ fractions for these two cases are $26 \%$ and $82 \%$, respectively, determined from the relative areas of the fitted components.

The Raman spectrum (Figure 8) is also strongly dependent on the pulse length and varies in a manner consistent

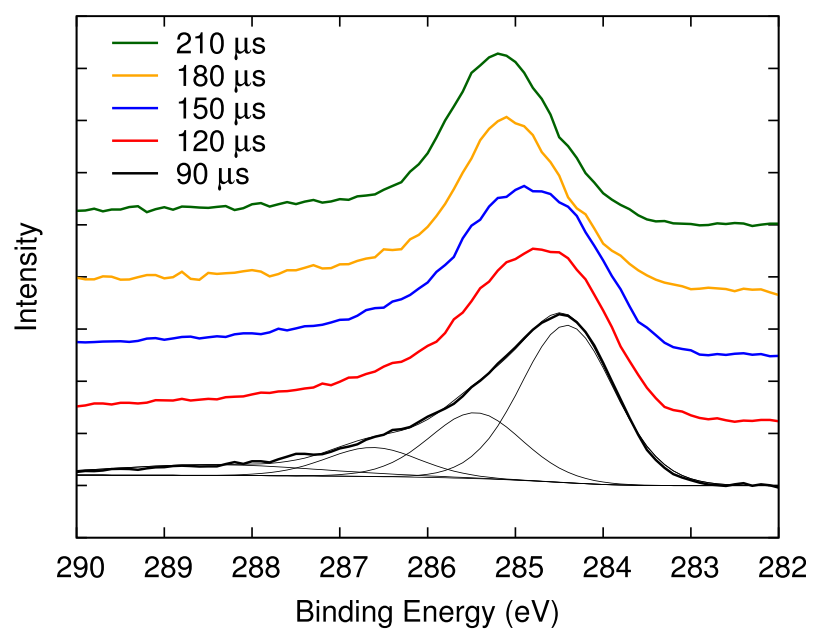

FIG. 7. XPS spectra for carbon films deposited using various pulse lengths as shown in Figure 1. The substrate bias was $-100 \mathrm{~V}$. For the film deposited with a $90 \mu$ s pulse length, the fitting components used to extract the $s p^{3}$ fraction are also shown.

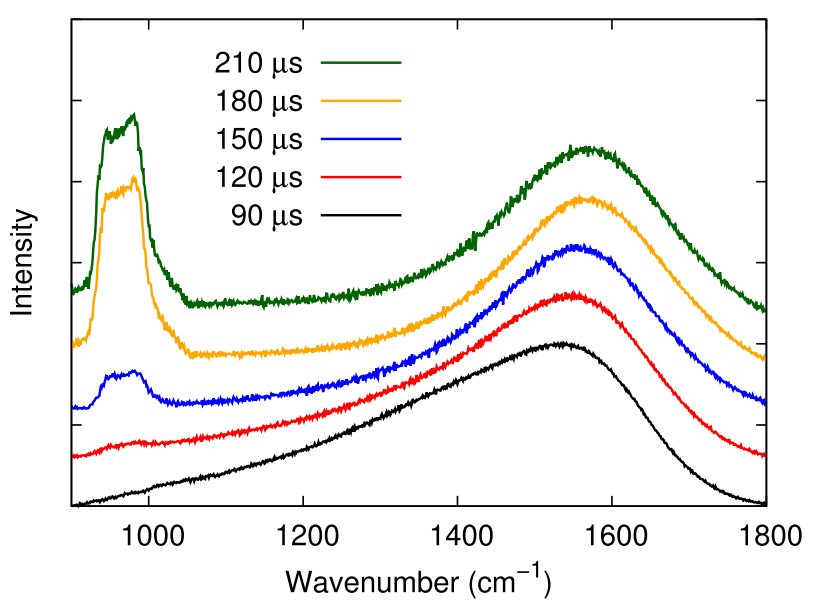

FIG. 8. Raman spectra for carbon films deposited using various pulse lengths as shown in Figure 1. The substrate bias was $-100 \mathrm{~V}$.

with the $s p^{3}$ fractions determined by XPS. For short pulse lengths, the peak around $1550 \mathrm{~cm}^{-1}$ is highly asymmetric, consistent with an amorphous carbon with a low $s p^{3}$ fraction. With increasing pulse length (and $s p^{3}$ fraction), this peak becomes increasingly symmetric. The square-topped feature around $950 \mathrm{~cm}^{-1}$ is a second-order peak of the silicon substrate. ${ }^{37}$ It becomes more prominent at longer pulse lengths where the carbon films are more transparent.

Figure 9 shows the dependence on pulse length of the film $s p^{3}$ fraction, Tauc gap, Raman $Q$ asymmetry coefficient, and film stress for substrate bias voltages of -100 and $0 \mathrm{~V}$. The $-100 \mathrm{~V}$ data for the $s p^{3}$ fraction and the Raman $Q$ coefficient were extracted from the spectra shown in Figures 7 and 8. Each of the four quantities plotted reflects the tetrahedral character of the film: a ta-C film will have a high $s p^{3}$ fraction, a Tauc gap approaching $3 \mathrm{eV},{ }^{7}$ a symmetric Raman peak, typically with a $Q$ fitting parameter approaching $-20,{ }^{37}$ and a film stress of above $6 \mathrm{GPa} .{ }^{38}$

The samples deposited at $-100 \mathrm{~V}$ bias show a monotonic increase in each quantity with the pulse length. A jump in each quantity occurs between the 150 and $180 \mu$ s samples, corresponding to the onset of mixed-mode operation, and the samples deposited with pulse lengths of 180 and $210 \mu$ s meet the criteria for $t a$-C. In contrast, at $0 \mathrm{~V}$ bias, all four quantities have little if any dependence on the pulse length, and none of these samples exhibit a tetrahedral character. This demonstrates that mixed-mode deposition, as opposed to conventional HiPIMS, is necessary for the deposition of $t a$-C. Further, the fact that $t a-\mathrm{C}$ does not form without a substrate bias, even in the case of mixed-mode deposition, demonstrates that while the mixed-mode discharge is an efficient source of carbon ions, their native energy is insufficient to access the tetrahedral form. This observation explains an aspect of the deposition rate data in Figure 2. For long pulse lengths, the deposition rate is lower when a negative substrate bias is used because the negative bias increases the density of the films, resulting in thinner films for the same incident flux of carbon.

Figures 10(a) and 10(b) show surface energy and contact angle data for the sample set examined in Figure 9. The $0 \mathrm{~V}$ films show little variation in their properties as the pulse length is varied. Using $-100 \mathrm{~V}$ bias, the surface 

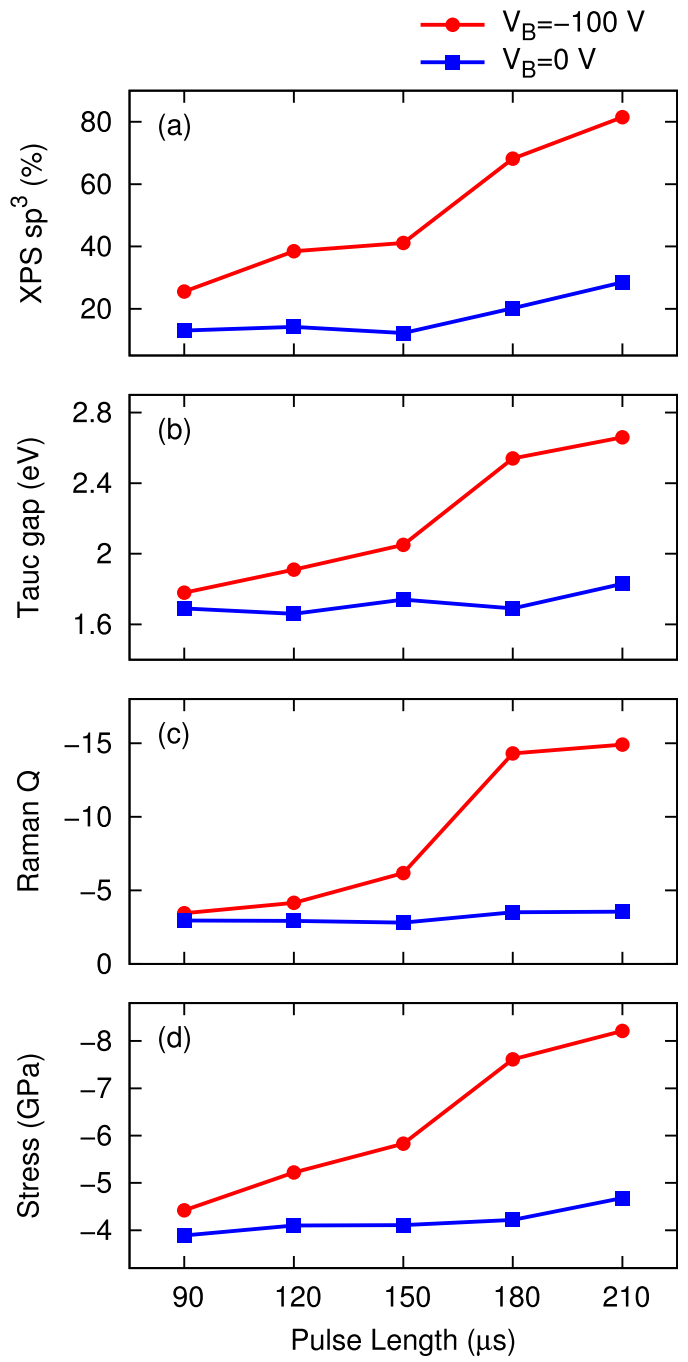

FIG. 9. Bulk properties of carbon films as a function of pulse length for two different substrate biases. Films with high diamond-like character are obtained only with pulse lengths of 180 or $210 \mu$ s and a substrate bias of $-100 \mathrm{~V}$. (a) $s p^{3}$ fraction determined by XPS; (b) Tauc gap determined using ellipsometry; (c) fitting parameter $Q$ quantifying the asymmetry of the Raman spectrum; (d) compressive stress determined by substrate curvature.

becomes increasingly hydrophobic as the pulse length increases. The data for the most tetrahedral film $(210 \mu$ s and $-100 \mathrm{~V}$ ) compare well with literature values of $75-80^{\circ}$ for the $t a-\mathrm{C}$ water contact angle $\mathrm{e}^{39,40}$ and $43 \mathrm{mN} / \mathrm{m}$ for the $t a-\mathrm{C}$ surface energy. ${ }^{39}$

The roughness values of the samples as measured with atomic force microscopy are shown in Figure 10(c). The films become slightly smoother with increasing pulse length, and the films deposited at $-100 \mathrm{~V}$ have a roughness $0.15 \mathrm{~nm}$ less than those deposited at $0 \mathrm{~V}$. The two most tetrahedrally bonded films $(-100 \mathrm{~V}, 180$ and $210 \mu \mathrm{s})$ have roughness values of $0.11 \mathrm{~nm}$, essentially the same as the literature value for $t a-\mathrm{C}$ of $\sim 0.12 \mathrm{~nm}$ as measured by Casiraghi et al. ${ }^{41}$

\section{DISCUSSION AND CONCLUSION}

Our recent study of mixed-mode HiPIMS deposition ${ }^{28}$ showed that tetrahedral amorphous carbon can be synthesized using a magnetron sputtering apparatus. In that work, the
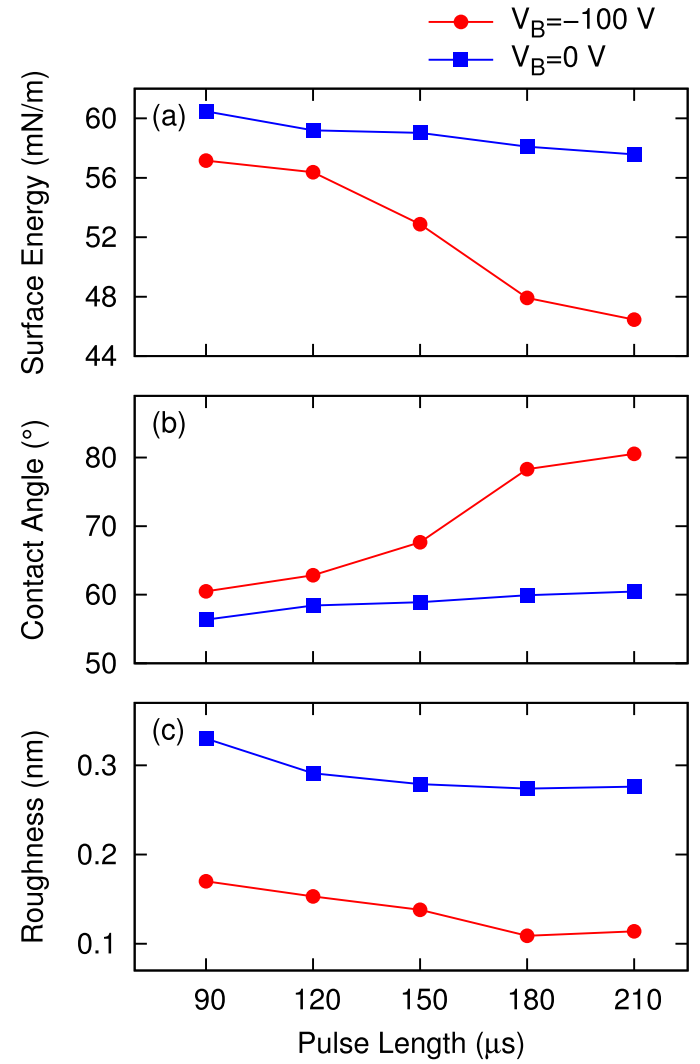

FIG. 10. Surface properties of carbon films as a function of pulse length for two different substrate biases; (a) surface energy, (b) water contact angle, and (c) AFM roughness. As described in the text, the data for the film deposited with a pulse length of $210 \mu$ s and bias of $-100 \mathrm{~V}$ are similar to literature values for $t a-\mathrm{C}$ films.

repeated triggering of short-lived arcs on the target was identified as a significant source of carbon ions. This conclusion was based upon optical emission spectroscopy, visual similarities with cathodic arcs, a minimum average ion energy of $20 \mathrm{eV}$ inferred from the substrate current, and a high $s p^{3}$ fraction in deposited films. The Ar pressure was found to be an important deposition parameter, with values above $0.3 \mathrm{~Pa}$ resulting in films with low tetrahedral character.

In this work, we examine two other important process parameters: the length of the pulse to the magnetron and the substrate bias voltage. The former indirectly determines the ionised fraction of the deposited species, whereas the substrate bias sets the energy of these ions as they impact the substrate. We also present a comprehensive characterization of the bulk and surface properties of the deposited carbon films, extending upon our earlier work by including data for hydrogen content, hardness, surface energy, and roughness.

The pulse length is an important deposition parameter that controls the ionized fraction of the plasma by determining whether or not mixed-mode deposition occurs. For short pulse lengths, the deposition flux arises from a pure HiPIMS glow discharge, while for pulse lengths longer than $150 \mu \mathrm{s}$, an increasing fraction of material is generated by the mixedmode arcs as shown in Figure 1. The formation of $t a-\mathrm{C}$ can be definitively attributed to the arc component of mixedmode operation, since when arcs are not present, the films deposited have low $s p^{3}$ content. Furthermore, the reason that 
the mixed-mode arcs produce this effect must be a substantially increased ionised fraction of $\mathrm{C}$ species in the plasma, because a high film $s p^{3}$ content is never obtained in samples deposited without bias, regardless of the pulse length used. The presence of these ions is additionally confirmed in Figure 6 by the appearance of the "energy window" effect typical of PVD ta-C deposition processes. These results mean that in mixed-mode deposition, the structure and properties of the deposited film can be tailored by the application of substrate bias in the same manner as is possible with deposition methods using ion beams. Mixed-mode deposition also affords an additional opportunity for control of the film growth as the ionised fraction of the plasma flux can be adjusted by varying the pulse length.

Finally, we note that many previous reports ${ }^{17-26}$ on deposition of carbon using HiPIMS have described films with $s p^{3}$ fractions of a maximum of $\sim 45 \%$. This result is reproduced in our work for short pulse lengths, where the mixed-mode arcs do not ignite: for pulse lengths of $150 \mu$ s or shorter, the maximum $s p^{3}$ fraction reached is $41 \%$. For the shortest pulse lengths, where the peak current is smallest, the $s p^{3}$ fraction declines further, as the sputtering process becomes closer to the case of a low-current DC magnetron discharge.

In conclusion, we have unambiguously demonstrated that the synthesis of $t a-\mathrm{C}$ by mixed-mode HiPIMS deposition is due to ionization arising from the arcs appearing at the end of the pulse. When the arcs are suppressed by early termination of the pulse or when the substrate bias voltage is set outside the optimal window, amorphous carbon films of low $s p^{3}$ content are produced. This result means that mixed-mode operation provides a carbon deposition flux where the fraction of species ionized is tunable to a high degree. This ability to control the ionized fraction of the deposited species is in addition to the usual ability to tune the energy of deposited ions by manipulation of the substrate bias. Having this extra degree of control opens possibilities for new carbon-based thin film designs. This deposition source could be used to synthesise a wide range of amorphous carbons, including graded coatings and multilayers where the $s p^{3}$ fraction is varied either continuously or abruptly during the deposition. Such a source would also be useful in other thin film applications where the presence of energetic ionized carbon species is of benefit such as the deposition of refractory carbides.

\section{ACKNOWLEDGMENTS}

The authors gratefully acknowledge support from the Australian Research Council. N.A.M. acknowledges a fellowship under FT120100924. We also thank Mihail Ionescu of the Australian Nuclear Science and Technology Organisation for performing the ERDA measurements.

\footnotetext{
${ }^{1}$ K. Bewilogua and D. Hofmann, Surf. Coat. Technol. 242, 214 (2014).

${ }^{2}$ J. Vetter, Surf. Coat. Technol. 257, 213 (2014).

${ }^{3}$ M. Stüber, S. Ulrich, H. Leiste, A. Kratzsch, and H. Holleck, Surf. Coat. Technol. 116-119, 591 (1999).

${ }^{4}$ J. J. Cuomo, J. P. Doyle, J. Bruley, and J. C. Liu, Appl. Phys. Lett. 58, 466 (1991).
}

${ }^{5}$ D. R. McKenzie, Rep. Prog. Phys. 59, 1611 (1996).

${ }^{6}$ S. Xu, B. K. Tay, H. S. Tan, L. Zhong, Y. Q. Tu, S. R. P. Silva, and W. I. Milne, J. Appl. Phys. 79, 7234 (1996).

${ }^{7}$ M. Chhowalla, J. Robertson, C. W. Chen, S. R. P. Silva, C. A. Davis, G. A. J. Amaratunga, and W. I. Milne, J. Appl. Phys. 81, 139 (1997).

${ }^{8}$ J. Schwan, S. Ulrich, H. Roth, H. Ehrhardt, S. R. P. Silva, J. Robertson, R. Samlenski, and R. Brenn, J. Appl. Phys. 79, 1416 (1996).

${ }^{9}$ F. Bernhardt, K. Georgiadis, L. Dolle, O. Dambon, and F. Klocke, Mat.wiss u. Werkstofftech. 44, 661 (2013).

${ }^{10}$ V. Kouznetsov, K. Macák, J. M. Schneider, U. Helmersson, and I. Petrov, Surf. Coat. Technol. 122, 290 (1999).

${ }^{11}$ U. Helmersson, M. Lattemann, J. Bohlmark, A. P. Ehiasarian, and J. T. Gudmundsson, Thin Solid Films 513, 1 (2006).

${ }^{12}$ J. Lin, J. J. Moore, W. D. Sproul, B. Mishra, J. A. Rees, Z. Wu, R. Chistyakov, and B. Abraham, Surf. Coat. Technol. 203, 3676 (2009).

${ }^{13}$ A. Anders, Surf. Coat. Technol 205(Suppl. 2), S1 (2011).

${ }^{14}$ J. Gudmundsson, N. Brenning, D. Lundin, and U. Helmersson, J. Vac. Sci. Technol. A 30, 030801 (2012).

${ }^{15}$ R. Bandorf, V. Sittinger, and G. Bräuer, "4.04-High Power Impulse Magnetron Sputtering-HIPIMS," in Comprehensive Materials Processing (Elsevier, Oxford, 2014), Vol. 4, pp. 75-99.

${ }^{16}$ A. P. Ehiasarian, R. New, W. D. Münz, L. Hultman, U. Helmersson, and V. Kouznetsov, Vacuum 65, 147 (2002).

${ }^{17}$ K. Sarakinos, A. Braun, C. Zilkens, S. Mráz, J. M. Schneider, H. Zoubos, and P. Patsalas, Surf. Coat. Technol. 206, 2706 (2012).

${ }^{18}$ S. P. Bugaev, V. G. Podkovyrov, K. V. Oskomov, S. V. Smaykina, and N. S. Sochugov, Thin Solid Films 389, 16 (2001).

${ }^{19}$ B. M. DeKoven, P. R. Ward, R. E. Weiss, R. A. Christie, W. Scholl, D. Sproul, F. Tomasel, and A. Anders, in 46th Annual Technical Conference Proceedings of the Society of Vaccum Coaters (2003), p. 158.

${ }^{20}$ L. A. Donohue, A. Torosyan, P. May, D. E. Wolfe, J. Kulik, and T. J. Eden, Plat. Surf. Finish., March 2009, pp. 38-46.

${ }^{21}$ S. Nakao, K. Yukimura, H. Ogiso, S. Nakano, and T. Sonoda, Vaccum 89, 261 (2013).

${ }^{22}$ M. Hiratsuka, A. Azuma, H. Nakamori, Y. Kogo, and K. Yukimura, Surf. Coat. Technol. 229, 46 (2013).

${ }^{23}$ K. Yukimura, H. Ogiso, S. Nakano, S. Nakao, and K. Takaki, IEEE Trans. Plasma Sci. 41, 3012 (2013).

${ }^{24}$ M. Huang, X. Zhang, P. Ke, and A. Wang, Appl. Surf. Sci. 283, 321 (2013).

${ }^{25}$ J. Lin, W. D. Sproul, R. Wei, and R. Chistyakov, Surf. Coat. Technol. 258, 1212 (2014)

${ }^{26}$ T. Konishi, K. Yukimura, and K. Takaki, Surf. Coat. Technol. 286, 239 (2016).

${ }^{27}$ M. Lattemann, A. Moafi, M. M. M. Bilek, D. G. McCulloch, and D. R. McKenzie, Carbon 48, 918 (2010).

${ }^{28}$ R. Ganesan, D. G. McCulloch, N. A. Marks, M. D. Tucker, J. G. Partridge, M. M. M. Bilek, and D. R. McKenzie, J. Phys. D 48, 442001 (2015).

${ }^{29}$ M. Lattemann, B. Abendroth, A. Moafi, D. G. McCulloch, and D. R. McKenzie, Diamond Relat. Mater. 20, 68 (2011).

${ }^{30}$ P. J. Fallon, V. S. Veerasamy, C. A. Davis, J. Robertson, G. A. J. Amaratunga, W. I. Milne, and J. Koskinen, Phys. Rev. B 48, 4777 (1993).

${ }^{31}$ J. Díaz, G. Paolicelli, S. Ferrer, and F. Comin, Phys. Rev. B 54, 8064 (1996).

${ }^{32}$ G. G. Stoney, Proc. R. Soc. A 82, 172 (1909).

${ }^{33}$ M. Kracica, C. Kocer, D. W. M. Lau, J. G. Partridge, J. E. Bradby, B. Haberl, D. R. McKenzie, and D. G. McCulloch, Carbon 98, 391 (2016).

${ }^{34}$ W. Oliver and G. Pharr, J. Mater. Res. 19, 3 (2004).

${ }^{35}$ C. A. Charitidis, Int. J. Refract. Met. Hard Mater. 28, 51 (2010).

${ }^{36}$ J. M. Jungk, B. L. Boyce, T. E. Buchheit, T. A. Friedmann, D. Yang, and W. W. Gerberich, Acta Mater. 54, 4043 (2006).

${ }^{37}$ S. Prawer, K. W. Nugent, Y. Lifshitz, G. D. Lempert, E. Grossman, J. Kulik, I. Avigal, and R. Kalish, Diamond Relat. Mater. 5, 433 (1996).

${ }^{38}$ D. W. M. Lau, D. G. McCulloch, M. B. Taylor, J. G. Partridge, D. R. McKenzie, N. A. Marks, E. H. T. Teo, and B. K. Tay, Phys. Rev. Lett. 100, 176101 (2008).

${ }^{39}$ J. S. Chen, S. P. Lau, Z. Sun, G. Y. Chen, Y. J. Li, B. K. Tay, and J. W. Chai, Thin Solid Films 398-399, 110 (2001).

${ }^{40}$ H. Han, F. Ryan, and M. McClure, Surf. Coat. Technol. 120-121, 579 (1999).

${ }^{41}$ C. Casiraghi, A. C. Ferrari, R. Ohr, A. J. Flewitt, D. P. Chu, and J. Robertson, Phys. Rev. Lett. 91, 226104 (2003). 